Araștırma Makalesi - Gönderim Tarihi: 02.09.2018 - Kabul Tarihi: 17.10.2018

\title{
Stratejik Lider Illetișimi ve Sosyal Medya: Türkiye’de Șirket Genel Müdürlerinin Twitter Kullanımı Üzerine Bir İnceleme ${ }^{1}$
}

\section{Ayșe Elif Posos Devrani²}

\begin{abstract}
Öz
Günümüzde halkla ilişkiler ve kurumsal iletişim pratiklerinde sosyal medyanın önemli bir araç olarak kullanıldığı gerçeği yadsınamaz. Sosyal medyanın içerik üretim, tüketim ve yeniden üretim süreçlerindeki çok kanallı yapısı, geleneksel halkla ilişkiler pratiklerindeki tek kanallı iletişim yapısına dair ezberi bozmuştur. Tüm bu gelişmeler, kurumsal iletişim alanındaki önemli bir çalışma kolu olan stratejik lider iletişimi alt başlığını da yeni fırsatlar, imkanlar ve tehditlere açmıştır.
\end{abstract}

Bu çalışmada, Fortune Türkiye 500 sıralamasındaki ilk 100 şirketin genel müdürlerinin Twitter özelindeki sosyal medya kullanımları incelenecektir. Kurumların doğal sözcüsü konumundaki üst düzey yöneticilerin, öncelikle Twitter'da ne kadar aktif oldukları, sonrasında ise paylaşımlarında bağlı bulundukları kurumun kimliğini kendi sosyal medya kullanımlarında bir politika olarak kabul edip etmediklerini sorgulanacaktır.

Anahtar kelimeler: kurumsal iletişim, halkla ilişkiler, dijital halkla ilişkiler, sosyal medya, lider iletişimi

Atıf: Devrani, Ayșe Elif Posos. (2018) Stratejik Lider Iletișimi ve Sosyal Medya: Türkiye'de Șirket Genel Müdürlerinin Twitter Kullanımı Üzerine Bir İnceleme. Akdeniz Üniversitesi İletișim Fakültesi Dergisi, (AKIL) Kasım (30) s. 77-88

1 Bu çalışma, 1-3 Kasım 2018 tarihleri arasında Akdeniz Üniversitesi İletişim Fakültesi tarafından düzenlenen 3. Uluslararası Medya Çalışmaları Sempozyumunda sözlü bildiri olarak sunulmuştur. Ayrıca bu çalışma Türk-Alman Üniversitesi Bilimsel Araştırma Projeleri Komisyonu'nca kabul edilen 2018BK0042 nolu proje kapsamında desteklenmiştir. .

2 Dr. Öğretim Üyesi, Türk-Alman Üniversitesi, Kültür ve Sosyal Bilimler Fakültesi, Kültür ve İletişim Bilimleri Bölümü, posos@tau.edu.tr 


\title{
Strategıc Leadershıp Communication And Socıal Medıa: A Study On Twitter Usage Among General Managers In Turkey
}

\begin{abstract}
Nowadays, it is a fact that social media is used as an important tool in public relations and institutional communication practices. The multichannel structure of social media in the processes of content production, consumption, and reproduction has been a challenge for one-channel communication of traditional public relations practices. All these developments open up new opportunities, possibilities and threats for strategic leadership communication, which is an important line of corporate communication.

In this study, the Twitter usage among the general managers of first 100 companies, which are on the Fortune Turkey 500 list, will be examined. It will be questioned whether the top managers, the institutions' natural spokesperson, are active in Twitter and whether they accept the corporate identity of their company as a policy in their social media use.
\end{abstract}

Keywords: corporate communication, public relations, digital public relations, social media, leadership communication 


\section{Giriș}

K urumsal iletişim, halkla ilişkilerin şirketlerin yönetim alanlarına girmesiyle ortaya çıkan bir iş alanıdır. Kurumsal iletişim şemsiyesinin altında etkinlik yönetimi, medya ilişkileri, kurumsal sosyal sorumluluk vb dış sosyal paydaşlarla birebir ilgili birimler olabileceği gibi, iç iletişim gibi iç sosyal paydaşlarla ilgilenen birimler de olabilmektedir. Bu faaliyet alanlarının hangilerinin kurum içinde istihdam edilen uzmanlarla hayata geçirileceği, hangilerinin kurum dışı profesyonel şirketlerden alınan hizmetlerle sağlanacağı ise kurumdan kuruma değişmektedir.

Sosyal medya yönetimi, kurumsal iletişimin altında değerlendirilen alanlardan biri olmuştur. Bazı şirketler sosyal medya yönetimini kendi kurumsal iletişim departmanlarının çatısının altında istihdam ettikleri uzmanlar ile yürütürken, bazı şirketler sosyal medya ajansları ile çalışmayı tercih etmekte, hatta sosyal medya ajansı, halkla ilişkiler ajansı ve reklam ajanslarının bütünleşik bir yapıda koordineli olarak işi yürütmesini beklemektedirler. Sosyal medya yönetimi, hem iç hem de dış sosyal paydaşları etkileyen, hedef kitle olarak belirleyen ya da mesaja konu edebilen bir alandır. Dolayısıyla bu başlık altında yapılan çalışmaları, hep tek bir faaliyet alanı ile özdeşleştirmek doğru olmaz.

Sosyal medyanın dünyadaki kurumsal iletişim trendlerinde kullanılma alanlarından biri de lider iletişimidir (Zerfass ve Sherzada, 2015: 292). Ancak bu kullanım, kendi içindeki bir çelişkiyi beraberinde getirir. Sosyal medya hesapları kişiseldir, ancak paylaşımlarkişinin tercihine göre- kamuya açık olabilmektedir. Geleneksel medya döneminde, her basın açıklaması kurumsal iletişim departmanı tarafından gözden geçirilen, vereceği mesaj üzerine titizlikle çalışılan, hangi bağlantının hangi kanal üzerinden mesajı alması gerektiği stratejik iletişim raporlarıyla öngörülü şekilde genel müdürler için belirlenmiştir (Zerfass \& Vercic \& Wisenerg; 2016) Ancak hem kurumsal iletişim profesyonellerinin, hem de genel müdürlerin ezberi, sosyal medyanın yeni düzeninde bozulmuştur. Bazı üst düzey yöneticiler, sosyal medyanın kişisel kullanımla kamuya erişim sağlayan yapısını doğru bir stratejiyle ve sosyal medya ajansı/kurumsal iletişim departmanı desteği ile kullanırken, bazısı da tamamen içgüdüsel şekilde ve denetimsiz olarak paylaşım yapmayı tercih etmektedir. Bu konudaki saha uygulamalarının yanı sıra, halkla ilişkiler ve yeni medya alanındaki akademik çalışmalar da, şirketlerdeki uygulamaları yakından takip etmeye başlamıştır (Hwang, 2012; cardwell\&Williams\&Pyle, 2017; Men ve Tsai, 2016; Huang ve Yeo; 2018).

Bu çalışmada, Türkiye'deki lider iletişiminin kurumsal şirketler düzeyinde sosyal medyayı ne derece mercek altına aldıklarına ilişkin sonuçlara varılmaya çalışılacaktır. Önce kurumsal şirketlerin stratejik iletişim yönetimine geçişine değinilecek, daha sonra stratejik iletişim planlamalarında ve kurumsal iletişim faaliyetlerinde sosyal medyanın rolüne değinilecek, son olarak Türkiye'nin önde gelen kurumsal şirketlerinin liderlerinin sosyal medya kullanımına dair sistematik bir araştırmanın bulguları paylaşılacaktır. 


\section{Stratejik İletișim Yönetimi ve Kurumsal Șirketler}

Belirli bir plana dahil edilerek yönetilen ve uygulanan tüm iletişim faaliyetlerini kapsayan stratejik iletişim yönetimi, sadece halkla ilişkilerin değil, insan kaynakları politikaları, uluslararası ve kültürlerarası iletişimin var olduğu tüm kamusal ve özel çalışma alanları, reklam ve pazarlama gibi çok kapsamlı bir iş alanının uygulamalarında karşımıza çıkar. Stratejik iletişimin varlığı, sözünü ettiğimiz iş alanlarının sağlıklı ve bütünlüklü işleyişi için elzemdir.

Bu makale kapsamında, stratejik iletişim yönetiminin geniş kapsamlı uygulama alanını daraltarak özel işletmeler bünyesindeki işleyişe odaklanılmıştır. Türkiye'deki kurumsal şirketlerin stratejik iletişim yönetiminden sorumlu kurumsal iletişim departmanları incelendiğinde, birbirinden farklı yapılarla karşılaşılır. Bazı şirketler kurumsal iletişim süreçleri tamamen kendi içinde istihdam ettikleri bir ekip ile yürütürken, çoğunluğu küçük bir kurumsal iletişim ekibiyle süreçleri yönetip iletişim faaliyetlerinin alt başlıklarını üçüncü taraflara delege etmektedir. Üçüncü taraf konumundaki iş ortakları; medya ilişkileri, etkinlik yönetimi, sosyal medya yönetimi gibi farklı alanlarda devamlı ya da proje bazlı olarak hizmet sağlamaktadır. Sosyal paydaşlarla olan ilişkiler bu alt başlıklarda yer alan faaliyetlerin yönetimi ile sağlanmaktadır. Hedef kitlelere ulaşmada mesajın ve aracın belirlenmesinde, lider etkili bir kanal, liderin sözü ise etkili bir mesaj olarak görülebilir. Farklı özellikteki sosyal paydaşlarla bu paydaşları özelliklerine bağlı olarak özelleştirilmiş mesajların aktarımında da lider ve liderin mesajı önemli bir rol üstlenir. Örneğin Grunig'in kitlelerin durumsal kuramında yer verilen ve mesajın kaynağı ile hiçbir sorun yaşamamış olanları kitle olmayanlar, kaynak ile sorunlu bir geçmişe sahip olan ve çözüme dair beklenti taşıyanları ise aktif kitleler olarak konumlandırırlar (Grunig, 2016). Bu konumlandırmanın gereği olarak da, her iki kitleye farklı mesaj farklı frekansta ve farklı araçlarla gönderilmelidir ki, kurumun stratejik iletişim yönetiminin gereği olarak mesaj doğru hedef kitleye doğru şekilde iletilebilsin. Grunig ve Hunt, farklı hedef kitlelerle farklı şekilde bağlantı kurma intiyacından hareketle "Bağlantı Kuramı"nı oluşturmuştur. Bu kurama göre, dört farklı bağlantı türüyle oluşturulan modelle farklı beklenti ve tipteki sosyal paydaşlarla sağlıklı bir ilişki kurulabilir. Dört bağlantı türünün isimleri ve tanımları özetle aşağıdaki gibidir (Rawlins, 2006: 3-5):

Kolaylaştırıcı bağlantı: Kurum üzerinde otorite sahibi olan ve karar mekanizmalarına direkt ya da indirekt etkileri bulunan sabit bağlantılardır. Yönetim kurulu, faaliyet alanına ilişkin karar merci konumundaki kamu görevlileri, yasa koyucular bu bağlantılara örnektir.

İşlevsel bağlantı: Kurumun faaliyet alanı için girdi ve çıktıların devamılıı̆ı için stratejik konumda olan sabit bağlantılardır. Örneğin, üretim sektöründe hizmet veren bir kurumun hammadde sağlayıcısı ve işçileri girdi için, üretilen maddenin alıcıları ise çıktı için stratejik konumdadır ve işlevsel bağlantılardır.

Normatif bağlantılar: Kurumun ortak bir hedefle hareket ettiği ya da çıkarlar doğrultusunda işbirliği içerisinde bulunduğu sabit bağlantılardır. Örneğin, belirli bir iş kolunda oluşturulan derneklerde, kurumla aynı sektörden olan diğer şirketler kurumun normatif bağlantılarıdır. 
Yaygınlaşmış bağlantılar: Sabit olmayan, tanımının sınırlarının belirlenmesi zor olan, frekansı ve içeriği kesin olarak söylenemeyecek şekilde ara sıra mesaj alışverişinde bulunulan bağlantılardır. Kurum için olay bazında çok stratejik bir konumda bulunabilirler.

Şirketlerin senelik olarak hazırladığı ve ara dönemlerde revize ettikleri stratejik iletişim planlarına bakıldığında, kriz anları da dahil olmak üzere tüm senaryoları ve bağlantıları kapsayan bir plan oluşturdukları görülür. Bu öngörülü ve değişime açık çalışma şekli, şirketlerin misyonunu yerine getirebilmek için hedef kitleleri ve sosyal paydaşları ile stratejik iletişime dayalı bir diyalog kurma çabası (Çınarlı, 2014: 24-25) içinde bulunma isteği ile örtüşmektedir.

\section{Stratejik Iletișimde Yeni Araç: Sosyal Medya}

Grunig ve Hunt, yürütülebilecek halkla ilişkiler modellerini dört kategoriye ayırırken, bu kategorilerin oluşturulmasındaki temel farklılığı iki temel değişkene bağlamaktadır: yön ve amaç (Güzelcik Ural'dan akt. Posos Devrani, 2014: 365) Yön, iletişimin iki yönlü ya da tek yönlü olup olmadığını ifade etmek için kullanılırken, amaç iletişim stratejisinin temelinde yatan sebep ya da ulaşılmak istenen sonucu ifade etmektedir (Posos Devrani, 2014: 365). Kurumsal şirketler stratejik iletişim planlarında denetimin görece zayıf olduğu ve diyalogun zorunluluk haline geldiği sosyal medyayı göz önünde bulundurarak iki yönlü simetrik modeli uygulamak durumunda kalmaktadır.

\section{Metodoloji}

\subsection{Araștırmanın Amacı}

Araştırmadaki amaç, Türkiye'deki kurumsal şirketlerin üst düzey yöneticileri konumundaki genel müdürlerin, sosyal medya kullanımını şirketlerinin stratejik iletişiminin bir parçası olarak kullanıp kullanmadıklarına dair bir durum analizi gerçekleştirmektir.

\subsection{Araștırmanın Evreni ve Örneklemi}

Araştırmada Fortune 500 tarafından 2018 yılında açıklanan ve şirketlerin 2017 verilerine göre yapılan sıralamadaki ilk 100 şirket evren olarak kabul edilmiştir (Fortune, 2018). Bu şirketlerin genel müdür ya da CEO’ları belirlenmiş, her üst düzey yöneticinin Twitter hesabı sorgulanmıştır. Twitter hesabı bulunan 21 üst düzey yöneticinin hesapları incelenmiştir.

\subsection{Araștırmanın Yöntemi}

Araştırmada yöntem olarak nitel bir yöntem olarak netnografi kullanılmıştır. Örneklemin oluşturulması için ön inceleme yapılmış ve 100 şirketin üst düzey yöneticileri belirlenmiştir. Devamında bu isimlerin Twitter'daki hesapları belirlenmiştir. Aynı ismi taşıyan, ancak isim benzerliği bulunan hesaplarla, sahte olduğu belirlenen hesaplar 
örneklem dışında bırakılmıştır. Son olarak, kurumsal iletişimin bir parçası olan lider iletişiminin bir aracı olarak Twitter kullanımını irdeleyebilmek için kategoriler oluşturulmuştur:

- Twitter hesabındaki bilgi kısmında, kişi şirketi ve şirket içindeki pozisyonunu belirtmiş midir?

- Twitter isminde şirketinin adı geçmekte midir?

- Twitter hesabı onaylı bir hesap mıdır?

- Twitter paylaşımları kişisel mi, yoksa kurumsal mıdır?

Şirketlerin üst düzey yöneticilerinin, 23-29 Temmuz 2018 tarih aralığına denk gelen 1 haftalık süredeki paylaşımları incelenmiş, Grunig ve Hunt'ın Bağlantı Kuramındaki dört farklı bağlantı kategorisi ile Twitter aracılığı ile iletişime geçilip geçilmediği sorgulanmıştır. Bunun için, belirlenen dönem içerisinde izlenecek yöneticilerin Twitte rhesapları, anonim bir hesap açılarak izlemeye alınmıştır.

\section{Bulgular}

Yapılan araştırmada, Twitter hesabı olduğu belirlenen üst düzey yöneticilerin şirket isimleri, Twitter hesapları ve kategoriler için oluşturulan soruların cevapları, Tablo 1'de yer almaktadır.

Tablo 1: Fortune 500 -2018 listesinde yer alan ilk 100 Şirketin Genel Müdür/CEO’larından Twitter Kullanıcısı Olanların Listesi ve Bilgileri

\begin{tabular}{|l|l|l|l|l|l|l|l|}
\hline Șirket Adı & $\begin{array}{l}\text { CE0/Genel } \\
\text { Müdür Adı } \\
\text { ve Soyadı }\end{array}$ & $\begin{array}{l}\text { Takip edilen Sayısı } \\
\text { Takipçi Sayısı }\end{array}$ & $\begin{array}{l}\text { Twitter } \\
\text { Hesabında } \\
\text { Șirket Adı } \\
\text { var mı? }\end{array}$ & Twitter Hesabı & $\begin{array}{l}\text { Hesap } \\
\text { sahibinin } \\
\text { bilgilerinde } \\
\text { iș yeri } \\
\text { ve unvan } \\
\text { belirtilmiș } \\
\text { mi? }\end{array}$ & $\begin{array}{l}\text { Hesap } \\
\text { onaylı } \\
\text { mı? }\end{array}$ \\
\hline Petrol Ofisi A.Ș. & $\begin{array}{l}\text { Selim } \\
\text { Șiper }\end{array}$ & 143 & 0 & & $\begin{array}{l}\text { https://twitter.com/ } \\
\text { selimsiper }\end{array}$ & & \\
\hline $\begin{array}{l}\text { Türk Hava Yolları } \\
\text { A.0. }\end{array}$ & Bilal Ekși & 39 & $\begin{array}{l}\text { 37.7 } \\
\text { Bin }\end{array}$ & + & $\begin{array}{l}\text { https://twitter.com/ } \\
\text { bilaleksithy }\end{array}$ & + & + \\
\hline Arçelik A.Ș. & $\begin{array}{l}\text { Hakan } \\
\text { Hamdi } \\
\text { Bulgurlu }\end{array}$ & 117 & 677 & & $\begin{array}{l}\text { https://twitter.com/h_ } \\
\text { bulgurlu }\end{array}$ & + & + \\
\hline $\begin{array}{l}\text { Türk } \\
\text { Telekomünikasyon } \\
\text { A.Ș. }\end{array}$ & $\begin{array}{l}\text { Paul } \\
\text { Doany }\end{array}$ & 24 & 16.600 & & $\begin{array}{l}\text { https://twitter.com/ } \\
\text { PaulDoany }\end{array}$ & + & + \\
\hline Turkcell & $\begin{array}{l}\text { Kaan } \\
\text { Terzioğlu }\end{array}$ & 1,253 & 35 Bin & & $\begin{array}{l}\text { https://twitter.com/ } \\
\text { search?q=Kaan\%20 } \\
\text { Terzio\%C4\%9Flu\&src=typd }\end{array}$ & + & + \\
\hline
\end{tabular}




\begin{tabular}{|c|c|c|c|c|c|c|c|}
\hline Enerjisa Enerji A.Ș. & $\begin{array}{l}\text { Ziya } \\
\text { Erdem }\end{array}$ & 985 & 389 & & https://twitter.com/erdemz & & \\
\hline Șok Marketler & $\begin{array}{l}\text { Uğur } \\
\text { Demirel }\end{array}$ & 227 & 1949 & & $\begin{array}{l}\text { https://twitter.com/ } \\
\text { ugurrdemirel }\end{array}$ & + & \\
\hline $\begin{array}{l}\text { İstanbul Gaz } \\
\text { Dağıtım San. Ve } \\
\text { Tic. A.Ș. }\end{array}$ & $\begin{array}{l}\text { Ali Ihsan } \\
\text { Sılkım }\end{array}$ & 16 & 611 & & $\begin{array}{l}\text { https://twitter.com/ } \\
\text { aliihsanslkm }\end{array}$ & + & \\
\hline Tosçelik & $\begin{array}{l}\text { Fuat } \\
\text { Tosyalı }\end{array}$ & 1007 & 4097 & & $\begin{array}{l}\text { https://twitter.com/fuat_ } \\
\text { tosyal?lang=tr }\end{array}$ & + & \\
\hline Ülker & $\begin{array}{l}\text { Mehmet } \\
\text { Tütüncü }\end{array}$ & 742 & 3746 & & $\begin{array}{l}\text { https://twitter.com/ } \\
\text { mehmet_tutuncu_ }\end{array}$ & & \\
\hline $\begin{array}{l}\text { Devlet Hava } \\
\text { Meydanları } \\
\text { İșletmesi Genel } \\
\text { Müd. }\end{array}$ & $\begin{array}{l}\text { Funda } \\
\text { Ocak }\end{array}$ & 79 & 5942 & + & $\begin{array}{l}\text { https://twitter.com/ } \\
\text { fundaocakdhmi }\end{array}$ & + & \\
\hline Teknosa & $\begin{array}{l}\text { Bülent } \\
\text { Gürcan }\end{array}$ & 264 & 1063 & & $\begin{array}{l}\text { https://twitter.com/ } \\
\text { bulentgurcan1 }\end{array}$ & & \\
\hline PTT & $\begin{array}{l}\text { Kenan } \\
\text { Bozgeyik }\end{array}$ & 70 & $\begin{array}{l}14.8 \\
\operatorname{Bin}\end{array}$ & & $\begin{array}{l}\text { https://twitter.com/ } \\
\text { bozgeyikkenan }\end{array}$ & + & + \\
\hline $\begin{array}{l}\text { Baștuğ Metalurji } \\
\text { San. A.Ș. }\end{array}$ & $\begin{array}{l}\text { Mustafa } \\
\text { Bağtuș }\end{array}$ & 14 & 425 & & $\begin{array}{l}\text { https://twitter.com/ } \\
\text { mbastug_ }\end{array}$ & + & \\
\hline Aksa & $\begin{array}{l}\text { Yașar } \\
\text { Arslan }\end{array}$ & 518 & 2376 & & $\begin{array}{l}\text { https://twitter.com/ } \\
\text { yasarars } \ln 1\end{array}$ & + & \\
\hline Borusan Otomotiv & $\begin{array}{l}\text { Hakan } \\
\text { Tiftik }\end{array}$ & 370 & 248 & & $\begin{array}{l}\text { https://twitter.com/ } \\
\text { hakantiftik }\end{array}$ & & \\
\hline İpragaz & $\begin{array}{l}\text { Eyüp } \\
\text { Aratay }\end{array}$ & 130 & 582 & & $\begin{array}{l}\text { https://twitter.com/ } \\
\text { eyuparatay }\end{array}$ & + & \\
\hline Defacto & İhsan Ateș & 66 & 3465 & & $\begin{array}{l}\text { https://twitter.com/ } \\
\text { ihsanates_ }\end{array}$ & + & \\
\hline $\begin{array}{l}\text { Mlp Sağlık } \\
\text { Hizmetleri A.Ș. }\end{array}$ & $\begin{array}{l}\text { Muharrem } \\
\text { Usta }\end{array}$ & 163 & 178B & + & $\begin{array}{l}\text { https://twitter.com/ } \\
\text { ustamuharrem?lang=tr }\end{array}$ & + & + \\
\hline Gen-Pa & $\begin{array}{l}\text { M. Fatih } \\
\text { Erdem }\end{array}$ & 668 & 360 & & $\begin{array}{l}\text { ttps://twitter.com/ } \\
\text { mfatiherdm }\end{array}$ & & \\
\hline Kordsa & $\begin{array}{l}\text { Cenk } \\
\text { Alper }\end{array}$ & 82 & 320 & & $\begin{array}{l}\text { https://twitter.com/ } \\
\text { cenkalper_ }\end{array}$ & + & \\
\hline
\end{tabular}

\subsection{Bilgi Kısmı ve Șirket Bilgileri}

Twitter hesabı bulunduğu belirlenen 21 üst düzey yöneticiden 16'sı çalıştıkları şirkete ve/veya şirketteki pozisyonlarına yer vermiştir. Ayrıca, pozisyonları dışında, spor 
takımı, köken, memleket gibi kendilerini tanımladıkları başka yönlerine de yer veren kişiler mevcuttur.

\subsection{Twitter Lakabı}

Twitter'da kullandıkları lakaplara baktığımızda, 21 kişinin de isimleri ya da isimlerinin birkaç harf eksiğiyle oluşturdukları kullanıcı isimleri tercih ettiklerini görmekteyiz. Tam isim kullanımı, kurumsal kullanımlarda sıklıkla karşımıza çıkan bir tercihtir. THY Genel Müdürü Bilal Ekşi ise, kullanıcı adında çalıştığı şirketin adını da koyarak kurumsal kimliğin içselleştirilmesinde en öne çıkan profil olmuştur.

\subsection{Onaylı Hesap}

21 üst düzey yöneticinin 5'inin Twitter hesapları onaylıdır. Bu beş hesaptan 4'ü, 10,000 'in üzerinde takipçiye sahipken, sadece biri 100,000'i aşkın takipçiye sahiptir. Onaylı hesaba sahip beş üst düzey yöneticinin Twitter hesaplarına ilişkin bilgileri Tablo 2'de derlenmiştir.

Tablo 2: Fortune 500 - 2018 Listesindeki Illk 100 Şirketin Üst Düzey Yöneticilerinden Onaylı Twitter Hesabına Sahip Olanların Bilgileri

\begin{tabular}{|l|l|l|l|}
\hline İsim ve Șirket & Takipçi Sayısı & Paylașım Sayısı & Hesap Bilgi Bölümü İçeriği \\
\hline Bilal Ekși - THY & 37,700 & 1,090 & $\begin{array}{l}\text { Genel Müdür. Türk Hava Yolları A.0./ CE0,Turkish } \\
\text { Airlines Inc. }\end{array}$ \\
\hline Paul Doany - Türk Telekom & 16,700 & 2,000 & $\begin{array}{l}\text { CEO (Customer Experience Officer) Heading } \\
\text { a team to Bridge the “Digital Divide” ' a } \\
\text { TurkTelekom. (previously: EmployeEpreneur - } \\
\text { CE0) }\end{array}$ \\
\hline Kaan Terzioğlu - Turkcell & 35,100 & 8,100 & Turkcell Genel Müdürü - CE0 IdTurkcell \\
\hline Kenan Bozgeyik - PTT & 14,800 & 1,950 & $\begin{array}{l}\text { Dünya Posta Birliği Idari Konsey Bașkanı/CA } \\
\text { Chairman of the UPU - PTT A.Ș. Yönetim Kurulu } \\
\text { Bașkanı, Genel Müdürü/PTT Corp. Chairman of } \\
\text { the Board\&Director General }\end{array}$ \\
\hline Muharrem Usta - MLP & 178,100 & 1,950 & ISU / Liv / MP \\
\hline
\end{tabular}

Onaylı hesap, Twitter tarafından şu şekilde tanımlanmıştır (Onaylanmış Hesaplar, Twitter, 2018): "Twitter'daki mavi onay rozeti kamuoyunun ilgisini çekebilecek bir hesabın orijinal olduğunun bilinmesini sağlar. ... Kamuoyunun ilgisini çekebileceği belirlenen bir hesap onaylanabilir. Bu hesaplar genellikle müzik, oyunculuk, moda, yönetim, politika, din, gazetecilik, medya, spor, iş dünyası ve diğer temel ilgi alanlarına sahip kullanıcılar tarafından kullanılan hesapları kapsar." Dolayısıyla, kendisini kurumunun sözcüsü olarak kabul eden birinin, gördüğü ilgiyle de doğru orantılı olarak Twitter'daki hesabını onaylatması beklenir. İnceleme göstermiştir ki, örneklemde yer 
alan üst düzey yöneticilerin çoğunluğu, kendilerini çalıştıkları kurumun sözcüsü görüp görmemek bir yana, Twitter'ı bu sözcülük için resmi bir kanal olarak kabul etmemektedir.

\subsection{Twitter Paylașımları}

21 üst düzey yöneticinin Twitter paylaşımlarına bakıldığında, çoğunluğun kendi şirketlerinin kurumsal hesaplarının paylaşımlarını tekrar paylaştığını görmekteyiz. İşlevsel bağlantı kategorisinde değerlendirilebilecek bu hesaplar, sadece şirketin ana kurumsal hesabı değil, alt markaların, marka sözcüsü konumundaki çalışanların, son kullanıcıların da hesapları olabilmektedir. Görülen bir diğer eğilim, işlevsel bağlantıların paylaşımları genelde üst düzey yöneticiler tarafından "retweet" yöntemiyle tekrar paylaşılmakta, karşılıklı bir paylaşım yapılmamaktadır.

Bir diğer yoğun paylaşım yapılan alan, devletim yönetim kadrosunda yer alan kişilerin ülke gündemine ilişkin paylaşımlarıdır. Bu paylaşımlar kolaylaştırıcı bağlantılar ile girilen iletişime örnektir.

Normatif bağlantılar konumundaki dernek ve STK'ların, aynı sektörden diğer şirketlerin paylaşımları ise, belirli kullanıcılarda yoğunluk göstermektedir. Özellikle STK ve derneklerde görev alan kullanıcılar, söz konusu STK ve dernekler her ne kadar çalıştıkları şirketler açısından normatif bağlantı konumunda olsa da, üst düzey yönetici için içinde bulunduğu bir oluşum olması sebebiyle işlevsel bağlantı olarak da konumlandırılabilmektedir.

Son olarak, kullanıcıların en az içerik ürettikleri alan, yaygınlaşmış bağlantılara yöneliktir. Birkaç istisna dışında, daha önce bahsedilen ve kategorize edilen iletişim alanının dışına çıkan kullanıcı sayısı çok azdır.

Twitter paylaşımlarında dikkat çeken bir diğer nokta, Türk Telekom'un Lübnan asıllı CEO'su Paul Doany'nin tüm paylaşımlarının Türkçe yapılmasıdır. Türkçe bilgisi yetersiz olan Doany'nin paylaşımlarının bir sosyal medya ajansı ya da sorumlu bir şirket çalışanı tarafından paylaşıldığı yönünde bir varsayıma varılmıştır.

\section{Sonuc}

Kurumsal iletişim süreçleri, hedefi ve mesajı belli, tehdit ve fırsatların göz önünde bulundurularak hazırlanmış yol haritaları olan, sürecin sonunda değerlendirmeye tabi tutularak iyileştirmenin mümkün kılındığı stratejik iletişim planlarına evrilmiştir. Bu değişim, stratejinin doğasında olan "bütünsellik"için gereklidir, çünkü ancak bu şekilde kurumsal iletişim süreçleri şirketin diğer çalışma alanları ve iş departmanları ile koordineli şekilde ilerleyebilir.

Kurumsal iletişim süreçlerine baktığımızda, sosyal medyanın günümüzdeki nüfuz alanının, sosyal medyanın bu süreçlere sadece basit bir "yeni araç" olarak dahil olmasının ötesine geçmesine neden olduğunu görürüz. Mesajın özelliklerinden, 
değerlendirme aşamasına, sosyal paydaşların belirlenmesinden, fırsat ve tehditlere kadar, her an değişime ve dönüşüme açık, aktif ve devamlılık arz eden bir bütünleşik iletişim sürecini hem mümkün hem zorunlu kılan, sosyal medyadır. Dolayısıyla sosyal medyayı, kurumsal iletişim süreçlerinde çift yönlü iletişim modelini gizlice dayatan bir konumda görmek yanlış olmaz.

Kurumsal iletişimin stratejik iletişim yöntemi bağlamında ele alındığında önemli bir alt başlığı olan lider iletişimi, geleneksel medyanın tekel döneminde tek tarafı iletişim modellerinin basın yapısının da getirdiği kolaylaştırıcılıkla öncelikli fırsatlar ve riskler taşımayan bir alandı. Muhakkak ki kurumsal imaj ve kurumsal kimlik için liderin duruşu, söylemi ve tutarlılığı büyük önem taşımaktaydı. Ancak yeni medya dönemiyle birlikte, özellikle sosyal medyanın yaygınlaşması ve kullanıcı ağının artmasıyla birlikte, kurumsal iletişimin her alt başlığında bazen araç, bazen değerlendirme alanı, bazen ise hedef kitle olarak karşımıza çıkan sosyal medya, lider iletişiminde de dikkat çekti. İki yönlü iletişime izin veren, talep, şikayet ve istekleri hızlı şekilde alma ve değerlendirme imanı tanıyan sosyal medya, kurum sözcüleri tarafından doğru ve dikkatli kullanıldığında krizler için önleyici olabilmekte, hatalı ve dikkatsiz kullanımı ise yeni krizlere sebep olabilmektedir. Ayrıca, sosyal medyanın kullanıcı için özel hayat ile iş hayatı arasındaki sınırı kaldıran ya da silikleştiren yapısı, kurum sözcüsü konumundaki üst düzey yöneticiler için zorlayıcı olabilmektedir. Yine de, bu silik sınırı kendi tarzı, duruşu, söylemi ve tutarlıı̆̆ını ile hem kendi kimliğinin izdüşümü, hem de kurumunun imajının güçlendirici bir öğesi olarak kullanabilen yöneticilere de rastlanmaktadır.

Bu araştırmada, Türkiye'de etkili olan ve Fortune 500'ün 2018'de açıklanan ilk 100 türk şirketinin başındaki iş insanlarının Twitter hesaplarının incelenmesiyle çıkan sonuçta, Türkiye'de gerek kurumsal iletişim süreçlerinde gerekse stratejik iletişim planlarında lider iletişiminin doğal ve yönetilmesi gereken bir öğesi olarak görünmediği ortaya konmuştur. 100 şirketin sadece 21 'inin üst düzey yöneticisi Twitter kullanıcısı olup, bunlardan 16'sı şirketlerini ve ünvanlarını bilgi kısmına taşımışlardır. 5 kullanıcının hesapları Twitter tarafından onaylatılmış olup, bu hesapların 21 hesaptan oluşan sıralamalarda en çok takipçili hesaplar olmaları dikkat çekicidir. İçeriklere bakıldığında ise, Grunig ve Hunt'ın dört bağlantı kategorisinden sabit bağlantı olan işlevsel, normatif ve kolaylaştırıcı bağlantılar ile Twitter araçsallaştırılarak iletişime geçilmekte olduğu görülmüştür. Yaygınlaştırılmış bağlantılarla olan iletişim ise oldukça kısıtlıdır. Özellikle teknoloji ve telekomünikasyon şirketlerinin üst düzey yöneticilerinin, diğer yöneticilere göre teknoloji editörleri ya da muhabirleri ile daha çok iletişime girdiği, dolayısıyla yaygınlaştırımış bağlantılarla karşılıklı iletişim içerisinde bulunduğu gözlemlenmiştir.

Yapılan araştırma, Türkiye'nin en büyük şirketlerinin üst düzey yöneticileriyle sınırlı kalmakla birlikte, bu şirketlerin kurumsallaşma ve dolayısıyla kurumsal iletişimde en yetkin konumda olduğu varsayımından hareketler, lider iletişiminin sosyal medyaya bakışına dair Türkiye'de genel kurumsal bakış açısını anlamak için değerlidir. Sonuçlar göstermiş̧tir ki, Twitter henüz lider iletişiminde etkin kullanılan bir araç değildir. Dahası, 21 Twitter kullanıcısı üst düzey yöneticinin sadece 5'inin onaylı hesap sahibi olması, şirketlerin lider iletişiminde Twitter'ı kurumsal kullanılan bir iletişim kanalı 
olmaktan çok, kurumsal haberlerin de paylaşıldığı bireysel bir iletişim kanalı olarak konumlandırdıklarını göstermektedir. Paylaşımlar incelendiğinde, farklı bağlantı kategorileri ile iletişime geçildiği görülmüştür. Ancak, bunun belirli bir stratejiyi takip ederek mi yapıldığı, yoksa Twitter'ın etkileşimi teşvik eden yapısından mı ileri geldiği sorusuna net bir cevap vermek mümkün değildir.

Sosyal medyayı stratejik iş planına dahil eden ve bu mecralarda alınan yansımaları ciddiye alarak aksiyon alma eğiliminde olan kurumsal şirketler, lider iletişiminde henüz sosyal medya kullanımını diğer faaliyet alanlarındaki kadar planlı ve detaylı yürütmemektedir. Türk Telekom, Turkcell ve THY örnekleri paylaşımların sıklığı ve farkı bağlantı kategorileriyle gündeme bağlı olarak etkileşim kurmalarıyla, profesyonel destek aldıkları düşünülmüştür. Diğer kullanıcıların paylaşımları ise, bireysel sebeplerle bireysel istekle Twitter kullandıklarını düşündürmektedir.

Son olarak, sosyal medyanın lider iletişiminde stratejik iletişim planına dahil edilme düzeyi hakkında daha geniş bir veriye ulaşmak için, Linkedln, Instagram, Facebook, Medium vb farklı sosyal medya hesaplarını kapsayan daha geniş bir veri setiyle çalışmak yararlı olacaktır.

\section{Kaynakça}

Cardwell, L. A., Williams, S., \& Pyle, A. (2017). Corporate public relations dynamics: Internal vs. external stakeholders and the role of the practitioner. Public Relations Review, 43(1), 152-162.

Çınarlı, İ. (2014). Stratejik İletişim Yönetimi Bağlamında Paydaş Kuramı'nın Eleştirel Bir Değerlendirmesi. İstanbul Üniversitesi Illetişim Fakültesi Dergisil Istanbul University Faculty of Communication Journal, (46), 23-36.

Çöklü, E . (2012). Etkili İşletmecilik Anlayışında İletişimin Rolü: Halkla İlişkilerin Öneminden Stratejik İletişim Yönetimine. İstanbul Üniversitesi İletişim Fakültesi Dergisi I Istanbul University Faculty of Communication Journal, 2 (12), . Retrieved from http://dergipark.gov.tr/iuifd/ issue/22877/244528

Fortune. Fortune 500-2018. http://www.fortuneturkey.com/fortune500 (Erişim Tarihi: 01.07.2018)

Grunig, J. E., Grunig, L. A., \& Dozier, D. M. (2006). The excellence theory. Public relations theory II, 21-62.

Huang, L. V., \& Yeo, T. E. D. (2018). Tweeting\# Leaders: Social media communication and retweetability of fortune 1000 chief executive officers on Twitter. Internet Research, 28(1), 123142.

Hwang, S. (2012). The strategic use of Twitter to manage personal public relations. Public Relations Review, 38(1), 159-161.

Onaylanmış Hesaplar, Twitter, https://help.twitter.com/tr/managing-your-account/about-twitterverified-accounts (Erişim Tarihi: 05.08.2018) 
Men, L. R., \& Tsai, W. H. S. (2016). Public engagement with CEOs on social media: Motivations and relational outcomes. Public Relations Review, 42(5), 932-942.

Posos Devrani, Ayşe Elif. (2015). "Sosyal Medya Türkiye'deki Halkla Illişkiler Pratiklerini Nasıl Değiştirdi? Halkla İlişkiler Alanında Çalışan Profesyonellerle Yapılan Anket Çalışması.” In . 1. Uluslararası Yeni Medya Yeni Yaklaşımlar Konferansı Bildiri Kitabı. Çanakkale, 8-9 Mayıs 2014.

Rawlins, B. L. (2006). Prioritizing stakeholders for public relations. Institute for Public Relations, 1-14.

Zerfass, A., \& Sherzada, M. (2015). Corporate communications from the CEO's perspective: How top executives conceptualize and value strategic communication. Corporate Communications: An International Journal, 20(3), 291-309.

Zerfass, A., Verčič, D., \& Wiesenberg, M. (2016). Managing CEO communication and positioning: A cross-national study among corporate communication leaders. Journal of communication management, 20(1), 37-55. 